\title{
MIGRANTES RETORNADOS CON DISCAPACIDAD Y SUS LUCHAS POR RECONOCIMIENTO: UNA MIRADA DESDE LA PASTORAL DE MOVILIDAD HUMANA DE HONDURAS
}

\author{
Returned migrants with disabilities and their struggles for recognition: \\ a look from the Pastoral Care of Human Mobility of Honduras
}

\author{
Nyzelle Juliana Dondé* \\ Tuila Botega**
}

Honduras es conocido como uno de los países de mayor emigración en América Latina. Los movimientos migratorios individuales o colectivos (caravanas), gritan por oportunidades de días mejores, seguridad, supervivencia, por acceder a los servicios sociales básicos, siendo estos algunos de los factores de expulsión que los obligan a enfrentar la ruta migratoria de Centroamérica (Canales, Rojas, 2018), en busca de una vida digna.

En el corredor migratorio Honduras-Guatemala-México-Estados Unidos, algunos inmigrantes tienen sus sueños interrumpidos, sea por la deportación, sea porque retornan a Honduras con alguna forma de discapacidad física, fruto de un accidente que les amputó partes de su cuerpo. A esta población, la Pastoral de Movilidad Humana de Honduras (PMH) dedica acompañamiento, impulsándolos a dar un nuevo sentido a su existencia y capacitándolos a la reinserción laboral en las comunidades y sociedad. Además, la pastoral apoya iniciativas de autoorganización, advocacy en la lucha por reconocer sus demandas específicas, siendo este el tema que será abordado en este reporte.

\section{Honduras de los migrantes}

La República de Honduras tiene una extensión territorial de 112.492 $\mathrm{km}^{2}$. Su población es de 9.352.088 millones de habitantes ${ }^{1}$, de los cuales $49 \%$ son hombres y $51 \%$ son mujeres. La actual División Política consta de

\footnotetext{
Misionera scalabriniana, Coordinadora Nacional de la Pastoral de Movilidad Humana en Honduras. Tegucigalpa, Honduras. E-mail: pmhhonduras5@gmail.com. Orcid: https://orcid. org/0000-0001-5658-5261.

** Investigadora del Centro Scalabriniano de Estudos Migratórios - CSEM. Brasília, DF, Brasil. E-mail: tuilabotega@gmail.com. Orcid: https://orcid.org/0000-0003-1412-2909.

1 Fuente: <https://www.ine.gob.hn/V3/V3/>. Acceso en 27.10.2020.
} 
18 departamentos, 298 municipios, 3.731 aldeas y 30.591 poblados, datos conforme el Instituto Nacional de Estadística de Honduras - INE (2020).

Honduras hace parte del Triángulo Norte de Centroamérica, bien como Guatemala y El Salvador, países que presentan una realidad de alto índice de corrupción e impunidad que resulta en altos niveles de pobreza, pobreza extrema y violencia generalizada. Es cada vez más reconocido el hecho de que el grueso de esta migración se debe a la falta de opciones para la permanencia en los países de origen (CEPAL, 2019, p. 176). Estos factores, sobre todo en Honduras, producen un flujo permanente y creciente de emigración irregular hacia países desarrollados, principalmente Estados Unidos, Canadá, España e Italia, así como los desplazamientos internos. Estimase que en Honduras cerca de 250 mil personas se han desplazado internamente por la violencia en los años de 2004 a 2018, sin embargo, esta es todavía una realidad poco visible (CIPPDV, 2019).

El país constituye un lugar no sólo de origen, sino también de tránsito, destino y retorno de un importante número de migrantes. Más recientemente, y al igual que sus vecinos regionales, el país ha servido como puente de un importante flujo de personas que emigraron desde otros países de la misma región y de otras regiones como Cuba, Haití, países de África, etc.

Según la Comisión Económica para América Latina - CEPAL (2018) ${ }^{1}$, estimase que $55,7 \%$ de los hondureños viven en situación de pobreza y 19,4\% en situación de extrema pobreza, la mayor parte de esta población reside en áreas rurales. Siendo uno de los países con mayor índice de pobreza de América Latina, circunstancia agravada por la pandemia Covid-19, esta situación tiende a agudizarse. Asimismo, es importante destacar el tema de las remesas, teniendo en vista que gran parte de la población emigrante hondureña en el exterior envía remesas a su familia, como estrategia de diversificación de fuentes de ingreso para el hogar en Honduras.

En síntesis, en Honduras, los problemas estructurales que promueven la migración se deben a la precaria inserción de la población en el sistema laboral y un limitado ingreso salarial, ante la ausencia de políticas educativas que desarrollen en la población esas capacidades técnicas, intelectuales y cualificadas que requiere el sistema productivo; la existencia de una política laboral fragmentada que reproduce las brechas laborales y salariales y una política de salud pública con grandes rajas que bloquean el acceso de la población a dichos servicios (López Sánchez, 2018).

2 Fuente: <https://estadisticas.cepal.org/cepalstat/Perfil_Nacional_Social.html?pais=HND\&idio $\mathrm{ma}=$ spanish $>$. Acceso en: 27.10.2020. 
Significativa es la cantidad de repatriaciones que suben cada año. Según el Observatorio Consular y Migratorio de Honduras - CONMIGHO${ }^{2}$, en 2018, 75.279 personas fueron deportadas. En 2019, 109.185 personas. Y, en este año atípico de 2020, debido a la pandemia del Covid-19, dónde las fronteras tenían la orden de "cierre", regresaran al país más de 30 mil migrantes, hasta la fecha. Sobre las deportaciones de este año, también cabe señalar que la mayoría de ellos son deportados de México (58\%), Estados Unidos (40\%) y una minoría (2\%) desde otros países de América Central. Es un flujo predominantemente masculino, aunque tiene un número considerable de mujeres y niños.

Un gran y común problema en lo que se refiere a los flujos de migración de retorno concierne a la capacidad de respuesta de las autoridades para atender las necesidades de los retornados. Muchos de ellos son deportados tras pasar largos períodos en el exterior y haber roto los lazos familiares; otros retornan con discapacidad debido a accidentes sufridos en la ruta migratoria. Emergen, por lo tanto, nuevas necesidades, tales como el apoyo psicosocial y la reinserción en el mercado laboral, que tiene escasas oportunidades de empleo y bajos salarios (CEPAL, 2019, p. 176).

Este es el contexto en el que actúa la Pastoral de Movilidad Humana en Honduras, organizada por las Hermanas Misioneras de San Carlos Borromeo Scalabrinianas en el año de 1991, a pedido de la Iglesia Católica, preocupada en dar respuestas a las necesidades de los migrantes y sus familiares. A lo largo de estos casi 30 años ya se escucharon muchas historias de dolor y sufrimiento, todavía algunas de éxito y de esperanza.

\section{Accidentes en la ruta migratoria}

Mi nombre es Óscar Reiniero Quintanilla Benites. En agosto del 2015 tomé la decisión de emigrar hacia Estados Unidos, recuerdo haber salido de mi casa el 9 de agosto y haber entrado a Guatemala ese mismo día y continué mi viaje por México, a los días ingresé por la frontera de El Ceibo y caminé aproximadamente 11 horas para llegar a la Casa del Migrante de Tenosique-México, ahí estuve varios días esperando el tren. El 16 de agosto como a las 5:00pm, al intentar subir al tren "La Bestia" me caí, y lamentablemente me lastimé bastante el pie, después de esto, me auxiliaron unas de Villa Hermosa en Tabasco, ahí me atendieron y me amputaron el pie izquierdo. Al día siguiente las autoridades de Migración me llevaron a una estación de migrantes, ahí estuve un mes encerrado, casi no me daban atención médica. Me deportaron el 14 de septiembre del año 2015.

El regreso a mi hogar fue difícil, mis vecinos y familia me esperaban con gran tristeza, pero siempre con las ganas y el deseo de apoyarme para que yo pudiera continuar con mi vida. Al poco tiempo de mi regreso empecé a recibir terapia física con el

3 CONMIGHO genera datos estadísticos del tema consular y migratorio en base a información fehaciente y comprobable, con el propósito de dar a conocer a la sociedad en general datos de los temas adscritos a la Subsecretaría de Asuntos Consulares y Migratorios. Disponible en: $<$ https://www.conmigho.hn/direccion-general-de-proteccion-al-hondureno-migrante/retorna dos-2020/>. 
objetivo de obtener una prótesis, de la cual ahora dependo, cuando ya estuve apto para andar, la recibí gracias a la ayuda de Dios y al apoyo de organizaciones.

Ahora cuento con una prótesis que me ayuda a movilizarme hacia mi trabajo, siempre con la ayuda de Dios y a pesar de todo, trabajo bien en el campo en la agricultura y con esto sobrevivo diariamente. Ya hace cuatro años tengo mi prótesis y con la ayuda de mi Dios he podido salir adelante, también gracias a mi familia y las organizaciones que me han ayudado para seguir con mi vida.

Vivo agradecido con Dios, con mi familia y con estas organizaciones, hoy en día, soy miembro de la Dirección General de la Comisión Nacional de Apoyo a Migrantes Retornados con Discapacidad y me siento muy satisfecho de poder estar participando. También me apoyaron a poder instalar una pequeña barbería en mi casa y ahora yo también apoyo a otros hermanos migrantes siendo un agente psicosocial de la Pastoral de Movilidad Humana. (Óscar Reiniero Quintanilla Benites, hondureño de 24 años)

En sus trayectorias por el corredor migratorio, los migrantes asumen diferentes riesgos. Hay los que tienen sus voces silenciadas y sus cuerpos desmembrados a causa de "La Bestia", el tren ferroviario destinado únicamente para cargas, pero que, sin embargo, es un medio que aún se usa para poder avanzar a las tierras mexicanas. Al intentar subir o bajar de los vagones del tren en movimiento, o al quedarse dormidos durante el trayecto, los migrantes pueden adquirir discapacidades físicas por amputación y/o lesiones medulares graves, en otros casos, incluso, hasta perder la vida. Aún, arriba de "La Bestia" pueden ser víctimas de robo, agresión, extorsión y/o ataques violentos perpetrados por otros migrantes, o por miembros de grupos criminales infiltrados, quienes los arrojan del tren si se niegan a pagar "la cuota" (COAMEX, 2019).

Al sufrir el accidente, son, una vez más, enmarcados por una narrativa xenofóbica, discriminatoria, aumentando significativamente el estigma sobre las personas migrantes regresadas (Albicker, Velasco, 2016) y con el reto de aprender a vivir con tal discapacidad.

Una vez que regresan al país con una discapacidad física, viviendo en la pobreza y sin alternativas en el sistema público de salud, la asistencia médica y psicológica es la principal necesidad de esta población. Siendo que, logrando su rehabilitación física y mental, pueden trabajar y lograr un proceso de reinserción integral.

La asistencia de salud a las personas retornadas con discapacidad física es una preocupación permanente, siendo que, en Honduras, la Pastoral de Movilidad Humana es la única organización que brinda acompañamiento a esta población migrante.

No hay hospitales y centros de salud suficientes para la atención de la población y los que existen carecen de personal, equipo técnico, medicamentos, ambulancias y todo tipo de accesorios necesarios para una asistencia de salud de calidad. La mayoría de las personas migrantes retornadas con discapacidad física necesitan de prótesis, otras de sillas de ruedas, o sea, permanentemente 
necesitan apoyo, pues tanto las prótesis como las sillas de ruedas tienen su tiempo de vida útil. Y, lastimosamente en el país no existe un programa gubernamental que brinde gratuitamente y de calidad prótesis y sillas de ruedas. Mismo las personas que usan prótesis o silla de ruedas necesitan de permanente atención médica porque es muy común que se les da infecciones de leves a severas, en ambas realidades se les tarda la recuperación por falta de medicación, productos de higiene y alimentación adecuada. En peor situación están aquellos que han sufrido una lesión medular o cerebral, que dependen diariamente de medicamentos, productos de higiene, pañales y alimentación especial.

En todos los casos, las personas migrantes retornadas con discapacidad física necesitan una atención psicosocial, siendo que, muchas veces, es necesario un acompañamiento personalizado e, incluso, muchas veces también los familiares, esposas, hijos, madres, como también aquellas personas que se convierten en cuidadoras de pacientes dependientes (parapléjicos, lesiones medulares/cerebrales), recalcando que el éxito de la rehabilitación depende en gran parte de una red de apoyo familiar, calcados en el amor y en la motivación.

En el contexto de la pandemia Covid-19 y con la llegada de la multi crisis que azotó al mundo, las personas con discapacidad, que ya se encontraban entre los más excluidos, sufrieron aún más los impactos devastadores que se pudieron ver tanto en los aspectos sociales como económicos en el salud física y mental, en el caso de un grupo en riesgo y de mayor vulnerabilidad, sujeto a ataques de ansiedad y depresión.

\section{Presencia de la Pastoral de Movilidad Humana junto a los migrantes retornados con discapacidad en perspectiva}

Inicialmente la atención brindada por la Pastoral de Movilidad Humana era principalmente a personas migrantes deportadas de Estados Unidos y México que llegaban al Centro de Atención al Migrante Retornado (CAMR) y Casa del Migrante San José de Ocotepeque. Pero, en 2006, fueron identificados los primeros migrantes retornados con discapacidad provenientes de México que llegaban vía aérea, e igualmente en las parroquias aumentaban el número de estos migrantes deportados vía terrestres en pésimas condiciones de salud.

En 2007, la Pastoral de Movilidad Humana realizó un primer diagnóstico en 3 departamentos: Yoro, Francisco Morazán y Comayagua. Fueron identificados 19 migrantes retornados con amputación a causa de un accidente en el tren en México. Dos años después, en el mes de febrero de 2009, se realizó la primera reunión para organizar la Comisión Nacional de Apoyo a Migrantes Retornados con Discapacidad Física (CONAMIREDIS), con el objetivo de identificar y buscar respuestas a las necesidades específicas de esta población migrante. 
La CONAMIREDIS ayuda en la promoción del desarrollo humano y la calidad de vida de las personas migrantes retornadas con discapacidad física a raíz de un accidente en la ruta migratoria, a través de la sensibilización en los diferentes sectores sociales y gobierno, de la gestión para el apoyo integral a las personas migrantes retornadas con discapacidad, de forma a favorecer un mejor futuro para ellas y sus familias.

A partir de las necesidades identificadas, en el año de 2010 se empezó a la organización de comités regionales, con el fin de que los Migrantes Retornados con Discapacidad Física (MRDF) pudieran sentirse apoyados, desarrollen sus habilidades y sean protagonistas de su propia historia y, juntos, luchen por sus derechos y mejores condiciones de vida. Fueron organizados cinco comités en Honduras: Tegucigalpa, Cedros, Vallecillo, Comayagua y Zona Norte.

Desde 2017, CONAMIREDIS es miembro fundador de la Alianza Regional de Migrantes y Retornados, una organización sin fines de lucro, apolítica e inclusiva, iniciativa de un grupo de migrantes retornados de Guatemala, Honduras y El Salvador, y con la experiencia y visión que La migración, y especialmente la migración de retorno, no es un problema en cada país, sino un problema regional. En ese sentido, la Alianza está fundamentada en integrar a los países de la región para velar por el cumplimiento de los derechos e intereses de la población migrante, retornada y discapacitada en tránsito.

En el 2019, se realizó un fortalecimiento organizacional, con la creación de la Dirección General de CONAMIREDIS, con el objetivo de promover la organización, la unidad, la inclusión, la solidaridad, el respeto, la lealtad y el compromiso entre los y las integrantes de la Dirección General, generando un ambiente de entendimiento y armonía en la organización y así lograr el objetivo común de brindar mayor funcionalidad y eficacia a la comisión, para la reivindicación de los derechos de los hondureños migrantes retornados con discapacidad física producto de la ruta migratoria.

Para priorizar la dimensión integral del ser humano, en todas las áreas atendidas por la Pastoral de Movilidad Humana hay profesionales de psicología que desarrollan un proceso continuo de apoyoen salud mental yacompañamiento psicológico. Por medio de la Red Nacional de Apoyo Psicosocial y Salud Mental (RENAPS) se puede tener una cobertura a nivel nacional. La RENAPS nace en 2016, con el apoyo técnico del Comité Internacional de la Cruz Roja (CICR) con el objetivo acompañar en salud mental a los migrantes y sus familias.

El tema de los migrantes amputados y de los migrantes que mueren en el camino, son de los aspectos que más duelen a la $\mathrm{PMH}$ y se exhorta al gobierno de Honduras que fije su mirada en estos rostros que buscan una vida más digna. En el caso de los amputados, pasan a formar parte de una larga lista de personas con discapacidad que no solo se encontrarán nuevamente de cara a la 
pobreza, sino que empezarán a sentir el rechazo e indiferencia de la sociedad y con esto, una casi nula oportunidad laboral.

La PMH cree en el trabajo en red $y$, junto con otras instituciones y organizaciones, ha desarrollado una labor en favor de los migrantes y sus familias. La CONAMIREDIS ha establecido vínculos con las siguientes instituciones: Dirección General de Asuntos Consulares, Dirección General de Migración y Extranjería, Centro de Atención al Migrante Retornado (CAMR), Cruz Roja Hondureña, Teletón San Pedro Sula, Hospital San Felipe, Proyecto Vida Nueva, Iglesia Católica de Honduras, Pan Para El Mundo, Conferencia Episcopal de los Estados Unidos, Iglesia Católica de Honduras, Cáritas de San Pedro de Sula, Cáritas de Yoro, Comité de Familiares de Migrantes Desaparecidos de El Progreso (COFAMIPRO) y Servicio Jesuita para Migraciones en Honduras.

Hoy la CONAMIREDIS es autogestionada por los migrantes retornados con discapacidad y, de manera articulada, cuenta con su plan operativo anual fortaleciendo las capacidades organizativas y técnicas de las comisiones, sistematizando informaciones para optimizar la toma de decisiones dentro de la Dirección General. De esta forma instala capacidades en todos los participantes, siempre de la mano con el acompañamiento psicosocial en salud mental.

Las experiencias y enseñanzas que traen las personas que sufrieron algún tipo de accidente y conviven con su discapacidad nos hacen recordar las palabras de Mons. Juan Bautista Scalabrini, Obispo de Piacenza, Norte de Italia, cuando se dirigía a los sordomudos en 1885 - y hoy perfectamente aplicable a la comunidad de las personas con discapacidad: "Están entre los más pobres e infelices: solitarios en medio del pueblo, excluidos de la sociedad humana, exiliado en su propio país. La fe y la caridad imponen no solo el deber de asistirlo, sino de readmitirlo en la sociedad civil y eclesial, con una instrucción que le ayude a interactuar con las personas y a través de la meditación humana, con Dios" (Scalabrini, 1989, p. 275).

La Pastoral de Movilidad Humana sigue la dinámica de evangelización en la realidad de los migrantes, movida por la mística scalabriniana, en los gestos concretos de acogida, promoción, protección e integración de los migrantes y sus familias. El motor que impulsa a ayudar la población migrante amputada y a enfrentar el constante reto de luchar por los derechos humanos básicos, por políticas públicas que los beneficien es la labor de cada nueva jornada.

Definitivamente, participar del acompañamiento sistemático de este colectivo de migrantes retornados con discapacidad, y percibir los logros, es una experiencia muy significativa. Cada persona con su familia es un ejemplo de superación, de resiliencia y cabe a nosotras, como agentes de la pastoral, apoyarlos en este proceso de tornarse el personaje principal de sus historias y de sus luchas por reconocimiento (Honneth, 2011) en cuanto sujetos de derechos. 


\section{Referencias bibliográficas}

ALBICKER, Sandra L.; VELASCO, Laura. Deportación y estigma en la frontera México-Estados Unidos: atrapados en Tijuana. Norteamérica, Año 11, n. 1, enero-junio, 2016.

CANALES, Cerón Alejandro I; ROJAS, Wiesner Martha Luz. Panorama de la migración internacional en México y Centroamérica. CEPAL - Serie Población y Desarrollo n. 124, 2018. Disponible en: < https://repositorio.cepal.org/bitstream/ handle/11362/43697/1/S1800554_es.pdf >. Acceso en: 27.10.2020.

Coalición México por los Derechos de las Personas con Discapacidad (COAMEX). Migración y Discapacidad. Una Mirada desde la Interseccionalidad. 2019. Disponible en: <http://coalicionmexico.org.mx/informes/migrantes19_f.pdf>. Acceso en: 27.10.2020.

Comisión Económica para América Latina y el Caribe (CEPAL). Panorama Social de América Latina, 2019. Santiago, 2019. Disponible en: <https://repositorio. cepal.org/bitstream/handle/11362/44969/5/S1901133_es.pdf>. Acceso en: 27.10.2020.

Comisión Económica para América Latina y el Caribe (CEPAL). CEPALSTAT. Bases de Datos y Publicaciones Estadísticas. Disponible en: < https://estadisticas.cepal.org/ cepalstat/Perfil_Nacional_Social.html?pais=HND\&idioma $=$ spanish $>$. Acceso en: 27.10.2020.

Comisión Interinstitucional para la Protección de las Personas Desplazadas Internamente por la Violencia (CIPPDV). Estudio de caracterización del desplazamiento interno por violencia en Honduras 2004-2018. 11 Diciembre 2019. Disponible en: <https://www.refworld.org.es/docid/5df3b7674.html>. Acceso en: 27.10.2020.

HONNETH, Axel. Luta pelo Reconhecimento: para uma gramática moral dos conflitos sociais. Biblioteca de Filosofia Contemporânea, Edições 70, 2011.

Instituto Nacional de Estadística de Honduras - INE. 2020. Disponible en: < https:// www.ine.gob.hn/V3//>. Acceso en: 27.10.2020.

LÓPEZ SÁNCHEZ, Bladimir. ¿Por qué se van de Honduras? Un análisis de la migración en un contexto de exclusión social. 2017. Disponible en: < http://cespad.org.hn/ wp-content/uploads/2018/11/Analisis-6-FINAL-CORRECCIONES.pdf>. Acceso en: 27.10.2020.

Observatorio Consular y Migratorio de Honduras - CONMIGHO. Datos sobre Hondureños retornados. 2018. Disponible en: <https://www.conmigho.hn/ direccion-general-de-proteccion-al-hondureno-migrante/retornados-2020/> . Acceso en: 27.10.2020.

SCALABRINI, Juan Bautista. Voz Actual. 1989. 